2004

\title{
Sexually violent predator laws: psychiatry in service to a morally dubious enterprise
}

Eric S. Janus

Mitchell Hamline School of Law, eric.janus@mitchellhamline.edu

Publication Information

364 Lancet, Dec. 2004, at 50

\section{Repository Citation}

Janus, Eric S., "Sexually violent predator laws: psychiatry in service to a morally dubious enterprise" (2004). Faculty Scholarship. Paper 180.

http://open.mitchellhamline.edu/facsch/180 


\title{
Sexually violent predator laws: psychiatry in service to a morally dubious enterprise
}

\begin{abstract}
This article discusses the role of psychiatrists in determining the treatment of sexually violent predators (SVP). Instead of being released at the end of their prison sentences, sex offenders in the USA who are judged mentally disordered and dangerous are being confined in secure "treatment facilities" for indeterminate terms. This novel and aggressive legislative tactic_embodied in US sexually violent predator laws-commandeers the traditional power of state mental health systems and puts it in service to a core function of the criminal justice system: the control of sexual violence. This transposition of "civil commitment" has forced psychiatry to legitimate and arbitrate the boundaries of an aggressive and highly contested form of state coercion. By their very structure, SVP laws politicize psychiatry in ways that go well beyond the traditional interconnection between psychiatry and law.
\end{abstract}

Keywords

SVP, sexual predators, civil commitment, rehabilitation, psychiatry

\section{Disciplines}

Criminal Law | Law and Psychology | Medical Jurisprudence 


\section{Sexually violent predator laws: psychiatry in service to a morally dubious enterprise}

Eric 5 janus

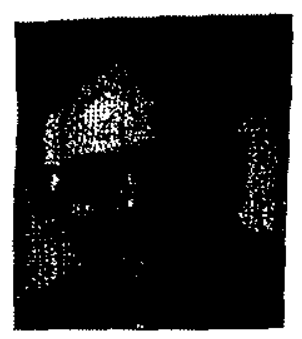

William Mitclehl College of Law, 875 Summir Avenue, St Paul, MHI S510S. USA

Correspondence to: Prof Erics janus ejanus@wmitchell.edu
Instead of being released at the end of their prison sentences, sex offenders in the USA who are judged mentally disordered and dangerous are being confined in secure "treatment facilities" for indeterminate terms. This novel and aggressive legislative tactic-embodied in US sexually violent predator (SVP) lawscommandeers the traditional power of state mental health systems and puts it in service to a core function of the criminal justice system: the control of sexual violence. This transposition of "civil commitment" has forced psychiatry to legitimate and arbitrate the boundaries of an aggressive and highly contested form of state coercion. By their very structure, SVP laws politicise psychiatry in ways that go well beyond the raditional interconnection between psychiatry and law.

SVP laws emerged in the early 1990 s to close a newly salient "prevention gap" in the control of sexual violence. The prevailing "law and order" mentality produced heightened societal concern. Conservative politics had abandoned the rehabilitation ideal in the criminal justice system, replacing release-when. rehabilitated "indeterminate" sentences with desert. based "determinate" sentencing. In the late 1980s, the first round of determinate sentences began to expire, leaving state officials without the discretion they had deployed under indeterminate sentences to adjust the length of confinement to the dangerousness of the offender.

By the late 1980s, heinous crimes committed by recently released sex offenders produced a popular call for more effective protection. Constitutional principles prohibited the lengthening of existing penal sentences. Civil commitment, whose non-penal pedigree exempted it from these constitutional constraints, was seen as the only available tool to continue the incarceration of sex offenders who were deemed "too dangerous to release" from prison.

Traditionally, civil commitment has been limited to medically recognised forms of mental illness or mental retardation that are considered so severe as to grossly impair an individual's competency to care for himself and is justified by the state's parens patriae power to care for those who cannot care for themselves. This power was constitutionally limited in the 1960 s to circumstances in which the mental impairment threatened some harm to self or others.

SVP laws are constructed to mimic civil commitment to partake of constitutional and moral legitimacy. SVP laws target "mental or personality disorders or abnormalities" that render the individual predisposed to commit further sexual crimes. SVP commitments are indefinite, although subject to periodic reexamination by the courts. Although their primary purpose is public safety, US states claim treatment as the secondan purpose of these laws.

SVP laws are both legally and morally controversial because they incarcerate individuals in anticipation of future predicted crimes. Their adoption of the civil commitment form appears to be ill.fitting and contrived. Most sex offenders are not incompetent and do not have the kinds of psychotic mental impairments that traditionally have justified civil commitment. SVP laws arc "preventive detention", accomplishing the morally and legally doubtful task of putting the "punishment" before the crime.

SVP laws politicise psychiatry and the allied professions in three ways. First, psychiatry and allied mental health professions are used by SVP laws as a central prop of legitimacy. The purpose of the laws is claimed to be legitimate because it is "medically" appropriate" to confine people with "mental disorders" for treatment in "treatment facilities". SVP laws claim that their application to individuals is legitimate becausc key determinants for confinement are certified by mental health professionals. The purpose and application of SVP laws are thereby made to appear scientific and inevitable, rather than contingent and political.

Second, the judgments made by professionals in SVP cases are largely political; they reflect socictal value judgments, and they are vulnerable to the pressures of the political process. Professionals judge whether the individual meets the legal criteria for a diagnosis based on mental condition and level of risk. These are questions that involve medical and psychological judgment and the application of legal thresholds. SVP experts are asked to calibrate their estimates against the legal thresholds for risk, which are expressed qualitatively using torms such as "likely" or "highly likely". Because these legal terms are so indeterminate, professionals must inake political judgments that determine the balance between public safety and individual liberty.

Similarly, mental health professionals decide whether individuals meet the legal mental disorder standard, which requires them to judge whether the disorder entails "serious difficulty in controlling behavior". This standard is apparently intended to invoke some notion of volitional dysfunction, a medically indeterminate concept of notorious opacity. To apply this standard professionals must take into account social and exper: judgments. 
Mental health professionals are asked to make the social judgment as to whether the individual is dangerous and mentally impaired enough to warrant long-term deprivation of liberty. But it would be naive to assert that the link between psychiatry and socio-politics is an invention of SVP laws. After all, psychiatric debate about the recognition and definition of psychiatric diagnoses often turns on social values. And psychiatric diagnoses and risk assessments play a ubiquitous role in the law and other social institutions.

But SVP laws push the politics beyond this normal range. SVP commitment decisions involve high stakes, pitting personal liberty against prevention of heinous crimes. False-negative errors in judgment result in sexual violence and are thus more visible and politically disvalued than are false positives. The political context is vurulent. Citizens protest proposed releases of predators and politicians scapegoat the mental health professionals whose judgments were in the chain of events ending in heinous crimes.

These political pressures are important because the legal questions posed are vague and the professional judgments tap into areas in which the expertise of mental health professionals is questionable or underdeveloped. Clinical assessment of risk for longterm recidivism is of questionable accuracy. Although strides are being made in the development of cmpirically based actuarial approaches, these tools remain rough guides to "group risk". Further, much remains unknown about assessing the effects of treatment or supervision on sex offender recidivism, so decisions about the safety of releasing individuals from commitment remain substantially unguided.

Even diagnosis is distorted by political pressures. Almost two decades ago, the American Psychiatric Association rejected the inclusion of "paraphilic rapism" or "paraphilic coercive disorder" in the Diagnostic and Statistical Manual of Mental Disorders. Yet these labels and other non-DSM diagnoses are now appearing with some frequency in SVP commitment proceedings.

The third way in which SVP laws politicise psychiatry is that the mental health infrastructure has been conscripted in ways that serve the political process, but are inconsistent with core professional values. Assessment of sexual dangerousness, even in its most developed form, is ethically inadequate to the task of deciding the long-term deprivation of liberty. Mental health institutions have also had the responsibility

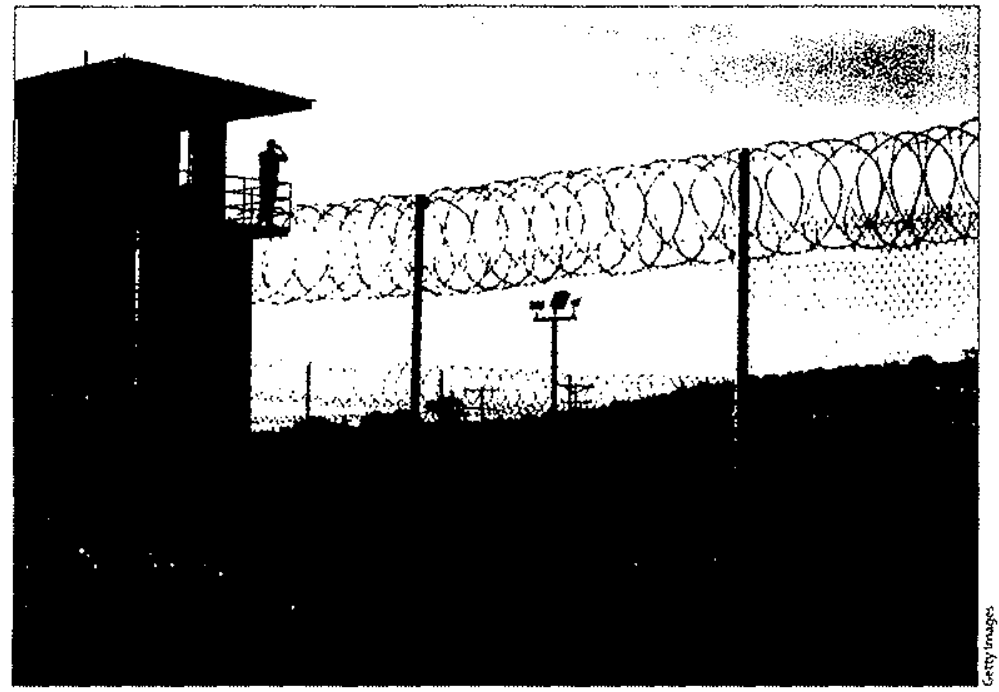

delegated to them for the care and treatment of committed "predators" despite the pronouncements of professional organisations that these laws "misallocate psychiatric facilities and resources [and] constitute an abuse of psychiatry," and "undermine the mission and integrity of the public mental health system".

SVP laws respond to powerful popular fears about the risk of sexual violence. Yet because they lock individuals away, not in punishment for past crimes, but in anticipation of uncommitted crimes, these laws threaten core democratic values and teeter on the verge of illegitimacy. Despite serious doubt and protest, psychiatry and its allied professions are recruited to legitimise the goals of these laws, to approve their application, and to assume institutional responsibility for the offenders who are confined.

There are three interrelated dangers here: first, the "good name" of psychiatry is misappropriated to burnish a morally dubious political enterprise. Second, psychiatric practice and the use of psychiatric knowledge are estranged from the profession's own ethics and values. Third, the political pressures underlying SVP laws may contaminate what should be politically neutral scientific judgments. Thus, while psychiatry is recruited and stretched to serve the legitimacy of SVP laws, this service may well undermine psychiatry's own claim to legitimacy.

\section{Further reading}

Dangerous sex offenders: a task force report of the American 9 sychiatric Association. Washington, DC: American Psychiatric Press, 1999.

Fitch LW. Sex offender commitment in the United States: legislative and policy concerns. Ann NY Acod SCi 2003: 989: 489-501.

Pientky RA, Janus ES. Seto MC, edis. Sexually coercive behavior: understanding and management. New York: New York Academy of Sciences. 2004.

Nationaf Association of State Mental Heaith Program Directors. Position staterrent on laws providing for the civil commitment of sexually violent criminal offenders. hitp //wnw.nasmhpdorg/gen sexpred.htm (accessed Nov 1. 2004). eral_files/position_stalement/ 